\title{
Dependence of Viscosity and Diffusion on $\beta$-Cyclodextrin and Chloroquine Diphosphate Interactions
}

\author{
Lenka Musilová ${ }^{1,2}$, Aleš Mráček 1,2,*(D), Eduarda F. G. Azevedo ${ }^{3}$, M. Melia Rodrigo ${ }^{4}$, Artur J. M. Valente ${ }^{3} \mathbb{D}$, \\ Miguel A. Esteso ${ }^{4,5}$ (D) and Ana C. F. Ribeiro ${ }^{3, *(\mathbb{D})}$
}

1 Department of Physics and Materials Engineering, Faculty of Technology, Thomas Bata University in Zlín, Vavrečkova 275, 76001 Zlín, Czech Republic; lmusilova@utb.cz

2 Centre of Polymer Systems, Thomas Bata University in Zlín, tř. Tomáše Bati 5678, 76001 Zlín, Czech Republic

3 Centro de Química de Coimbra, Department of Chemistry, University of Coimbra, 3004-535 Coimbra, Portugal; edy.gil.azevedo@gmail.com (E.F.G.A.); avalente@ci.uc.pt (A.J.M.V.)

4 Departamento de Química Analítica, Química Física e Ingeniería Química, Universidad de Alcalá, 28871 Alcalá de Henares, Spain; mmelia.rodrigo@uah.es (M.M.R.); miguel.esteso@uah.es (M.A.E.)

5 Departamento de Química, Universidad Católica Santa Teresa de Jesús de Ávila, 05005 Ávila, Spain

* Correspondence: mracek@utb.cz (A.M.); anacfrib@ci.uc.pt (A.C.F.R.); Tel.: +420-733-690-668 (A.M.); +351-239-854-460 (A.C.F.R.)

Citation: Musilová, L.; Mráček, A.; Azevedo, E.F.G.; Rodrigo, M.M.;

Valente, A.J.M.; Esteso, M.A.; Ribeiro, A.C.F. Dependence of Viscosity and Diffusion on $\beta$-Cyclodextrin and Chloroquine Diphosphate Interactions. Processes 2021, 9, 1433. https://doi.org/10.3390/pr9081433

Academic Editor: Si Wu

Received: 6 July 2021

Accepted: 11 August 2021

Published: 19 August 2021

Publisher's Note: MDPI stays neutral with regard to jurisdictional claims in published maps and institutional affiliations.

Copyright: (c) 2021 by the authors. Licensee MDPI, Basel, Switzerland. This article is an open access article distributed under the terms and conditions of the Creative Commons Attribution (CC BY) license (https:// creativecommons.org/licenses/by/ $4.0 /)$.

\begin{abstract}
Mutual diffusion coefficients of chloroquine diphosphate (CDP) in aqueous solutions both without and with $\beta$-cyclodextrin ( $\beta$-CD) were measured at concentrations from $(0.0000$ to 0.0100$) \mathrm{mol} \mathrm{dm}^{-3}$ and $298.15 \mathrm{~K}$, using the Taylor dispersion technique. Ternary mutual diffusion coefficients $\left(D_{\mathrm{ik}}\right)$ measured by the same technique are reported for aqueous CDP $+\beta$-CD solutions at 298.15 K. The presence of $\beta C D$ led to relevant changes in the diffusion process, as showed by nonzero values of the cross-diffusion coefficients, $D_{12}$ and $D_{21} \cdot \beta$-CD concentration gradients produced significant co-current coupled flows of CDP. In addition, the effects of $\beta$-CD on the transport of CDP are assessed by comparing the binary diffusion coefficient of aqueous CDP solutions with the main diffusion coefficient $\left(D_{11}\right)$ measured for ternary $\{C D P(1)+\beta-C D(2)\}$ solutions. These observations are supported by viscosity analysis. All data allow to have a better interpretation on the effect of cyclodextrin on the transport behavior of CDP.
\end{abstract}

Keywords: chloroquine diphosphate; diffusion; drugs; solutions; transport properties

\section{Introduction}

Chloroquine diphosphate (CDP) is a 4-aminoquinoline-based drug with a broad spectrum of applications, including all types of malaria infections and averse to cell growth and/or inducing cell death in human leukemia K562 cell [1-3]. CDP is also indicated for the treatment of inflammatory diseases and rheumatoid arthritis [4,5]. More recently, CDP has been highly cited as a consequence of its potential, though not confirmed, to treat severe acute respiratory syndrome coronavirus 2 [6].

CDP is soluble in water and characterized by having a high bioavailability when administrated orally [4]. However, this drug also shows some significant side effects [7]. These can be reduced by forming host-guest supramolecular compounds with cyclodextrins [2]. It is known that due to the amphiphilic behavior of cyclodextrins, supramolecular interactions mainly occur inside the hydrophobic CD's cavity with hydrophobic guests [8,9]. However, interactions between guest molecules and cyclodextrins can also occur via, for example, H-bonding involving hydroxyl groups located outside the CD's cavity $[10,11]$. Despite its solubility in aqueous solutions, the molecular structure of the CDP suggests the ability of the quinolone group to form host-guest supramolecular compounds with $\beta$-cyclodextrin. For example, Fan et al. have reported the complexation of 8-nitro-quinoline (at solid state) with $\beta$-cyclodextrin [12], whilst the equilibrium constant between quinolone and $\beta$-CD has been computed as equal to ca. $380 \mathrm{~L} \mathrm{~mol}^{-1}$ [13]. These values are in line 
with the binding constant of $1890 \mathrm{~L} \mathrm{~mol}^{-1}$ for a 1:1 CDP: $\beta$-CD complex obtained by Roy et al. [2]. Recently, it has been demonstrated by NMR and computational studies that chloroquine is able to protrude both $\alpha$ - and $\beta$-cyclodextrins, being that the stronger interaction occurs with the $\beta$-cyclodextrin [14].

Although much work has been done on the development of CDP-containing systems $[1,15]$, its kinetics in aqueous solution are still poorly understood. In the present paper, transport properties (diffusion coefficients and viscosities) of CDP in water and in aqueous solutions containing $\beta$-cyclodextrin are reported.

Specifically, we have measured binary diffusion coefficients of this drug in water, and multicomponent chemical ternary diffusion coefficients $\left(D_{11}, D_{22}, D_{12}\right.$ and $\left.D_{21}\right)$ for $\mathrm{CDP}(1)+\beta-\mathrm{CD}(2)$ aqueous solutions, using the Taylor dispersion technique. The behavior diffusion of these systems (binary and ternary) and the coupled flows occurring in the solution were studied in order to better understand if there are interactions between CD-CDP by estimating its association constant, leading to better insight of these systems' structure.

The comparison of Jones-Dole viscosity coefficients for CDP in water and in the $\left\{\right.$ water $\left.+\beta-C D 0.0070 \mathrm{~mol} \mathrm{dm}^{-3}\right\}$ mixture allowed to evaluate the solute-solvent interactions occurring in these solutions.

Additionally, interdiffusion coefficients correspond to the maximum limit value for the release kinetics of drugs (or complexes), in these systems.

\section{Materials and Methods}

\subsection{Materials}

Chloroquine diphosphate (CDP) (Merck) an $\beta$-cyclodextrin ( $\beta$-CD) (Sigma-Aldrich) were used as received, without further purification (Table 1). All solutions were freshly prepared and degassed by sonication before each experiment.

Table 1. Sample description.

\begin{tabular}{|c|c|c|c|}
\hline Chemical Name & Source & CAS Number & Purity \\
\hline $\begin{array}{l}\text { Chloroquine diphosphate } \\
\qquad(\mathrm{CDP}) \\
\left(\mathrm{C}_{18} \mathrm{H}_{26} \mathrm{ClN}_{3} \cdot 2 \mathrm{H}_{3} \mathrm{PO}_{4}\right)\end{array}$ & Merck & $50-63-5$ & mass fraction $\geq 0.98$ \\
\hline$\beta$-Cyclodextrin $(\beta-C D)$ & $\begin{array}{c}\text { Sigma-Aldrich } \\
\text { (water mass fraction of } 0.131 \text { ) }\end{array}$ & $7585-39-9$ & mass fraction $\geq 0.99$ \\
\hline Water & $\begin{array}{l}\text { Millipore-Q water }\left(\rho=1.82 \times 10^{5} \Omega \cdot \mathrm{m} \text { at }\right. \\
298.15 \mathrm{~K})\end{array}$ & $7732-18-5$ & \\
\hline
\end{tabular}

\subsection{Techniques}

\subsubsection{Viscosity Measurements}

For viscosity measurements, a set of $\mathrm{CDP}$ aqueous solutions were prepared at concen-

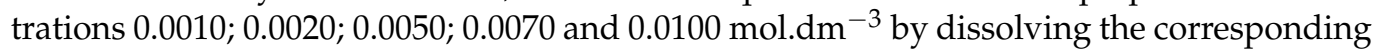
solid in pure water, under continuous stirring, at $298.15 \mathrm{~K}$. Likewise, another set of CDP solutions were also prepared in a mixture $\left\{\right.$ water $\left.+\beta-C D 0.0070 \mathrm{~mol} \mathrm{dm}^{-3}\right\}$ as solvent at the same concentrations above indicated and following the same procedure.

Viscosity measurements were performed using a microviscometer (Lovis $2000 \mathrm{ME}$ Anton Paar) at $298.15 \pm 0.01 \mathrm{~K}$. The average value of the viscosity data at each concentration was obtained from five independent measurements. The viscometer was calibrated with Milli-Q water (from A10 Millipore) before every set of experiments. The uncertainty of the values for this parameter was calculated as equal to $0.04 \mathrm{mPa} s$ based on calibration data. The repeatability of the experiments was $\pm 0.05 \%$.

\subsubsection{Diffusion Measurements}

Taylor dispersion technique for measuring diffusion in solutions has gained increasing popularity due to its fast and reliable analysis of multicomponent systems. 
The theory of the Taylor dispersion technique is well described in the literature [16-21] and, consequently, only a summarized description of both the apparatus and the procedure used in our study is presented here.

At the begin of each experience, a 6-port Teflon injection valve (Rheodyne, model 5020) was used to introduce $63 \mathrm{~mm}^{3}$ of solution into a laminar carrier stream with a flow rate of $0.17 \mathrm{~cm}^{3} \mathrm{~min}^{-1}$ leading retention times ca. $1.1 \times 10^{4} \mathrm{~s}$. The dispersion tube and the injection valve was kept at $298.15 \pm 0.01 \mathrm{~K}$ in an air thermostat. The radius of the tube is equal to $0.32200 \pm 0.00003 \mathrm{~mm}$. The monitoring of the injected samples dispersion, at the dispersion tube outlet, was done using a differential refractometer (Waters model 2410).

Detector voltages, $V(t)$, were measured by using a digital voltmeter (Agilent $34401 \mathrm{~A}$ ).

The diffusion of CDP in aqueous solutions (binary system) is described by Fick's equation

$$
J=-D \nabla C
$$

where $C$ is the molar concentration of the solute and $D$ the binary diffusion coefficient.

At the tube outlet, the distribution of the dispersed solute is followed by passing the carrier through a differential refractometer which gives a linear response to changes in $V(\mathrm{t})$ composition dependent property. Combining this detector output signal $V(\mathrm{t})$ and the equation derived by Taylor [22-24], that accurately describes the dispersion of the solutes, and that considers that the flow is laminar, the binary diffusion coefficients were evaluated by fitting the dispersion Equation (2) to the detected voltages. That is,

$$
V(\mathrm{t})=V_{0}+V_{1} t+V_{\max }\left(t_{\mathrm{R}} / t\right)^{1 / 2} \exp \left[-12 D\left(t-t_{\mathrm{R}}\right)^{2} / r^{2} t\right]
$$

$V_{1}$ the baseline slope, $V_{0}$ is the baseline voltage, $V_{\max }$ the peak height, $t_{\mathrm{R}}$ the mean sample retention time and $r$ the inner radius of the dispersion tube.

Ternary mutual diffusion coefficients $\left(D_{\mathrm{ik}}\right)$ of aqueous $\left\{\mathrm{CDP}\left(C_{1}\right)+\beta-\mathrm{CD}\left(C_{2}\right)\right\}$ solutions were computed by using coupled Fick equations (Equations (3) and (4)) $[20,21]$.

$$
\begin{aligned}
& J_{1}=-D_{11} \nabla C_{1}-D_{12} \nabla C_{2} \\
& J_{2}=-D_{21} \nabla C_{1}-D_{22} \nabla C_{2}
\end{aligned}
$$

$J_{1}$ and $J_{2}$ represent the molar fluxes of CDP (1) and $\beta$-CD (2), respectively, driven by the concentration gradients $\nabla C_{1}$ and $\nabla C_{2}$ of each solute 1 and 2 . Cross-diffusion coefficients $D_{12}$ and $D_{21}$ give the coupled flux of each solute, driven by a concentration gradient in the other solute. While a negative $D_{\mathrm{ij}}$ coefficient indicates countercurrent coupled transport of solute $i$ from regions of lower to higher concentration of solute $j$, a positive $D_{\mathrm{ij}}$ crosscoefficient $(i \neq j)$ indicates co-current coupled transport of solute $i$ from regions of higher to lower concentrations of solute $j$. Main diffusion coefficients $D_{11}$ and $D_{22}$ give the flux of each solute, driven by its own concentration gradient.

Ternary dispersion experiences were prepared by injecting $\{\mathrm{CDP}(1)+\beta-\mathrm{CD}(2)\}$ solution samples of composition $C_{1}+\Delta C_{1}, C_{2}+\Delta C_{2}$ into carrier streams of composition $C_{1}$, $C_{2}$. In the tracer diffusion studies, the concentration of the component studied under trace conditions was zero; that is, in the carrier solutions, for tracer of CDP, $=0, C_{2}=C_{2}$, and for tracer of $\beta-C D, C_{2}=0$ and $C_{1}=C_{1}$. Considering the equation that describes ternary dispersion profiles provided and that the flow is also laminar, whose development is well reported in references $[20,25,26])$, the ternary $D_{\mathrm{ij}}$ coefficients were calculated by fitting the Equation (5)) (Figure 1)

$V=V_{0}+V_{1}+V_{\max } \sqrt{\frac{t_{\mathrm{R}}}{t}} \frac{\left(a+b \alpha_{1}\right) \sqrt{D_{1}} e^{-12 D_{1}\left(t-t_{\mathrm{R}}\right)^{2} / r^{2} t}+\left(1-a-b \alpha_{1}\right) \sqrt{D_{2}} e^{-12 D_{2}\left(t-t_{\mathrm{R}}\right)^{2} / r^{2} t}}{\left(a+b \alpha_{1}\right) \sqrt{D_{1}}+\left(1-a-b \alpha_{1}\right) \sqrt{D_{2}}}$

being:

$$
\alpha_{1}=\frac{R_{1} \Delta C_{1}}{R_{1} \Delta C_{1}+R_{2} \Delta C_{2}}
$$




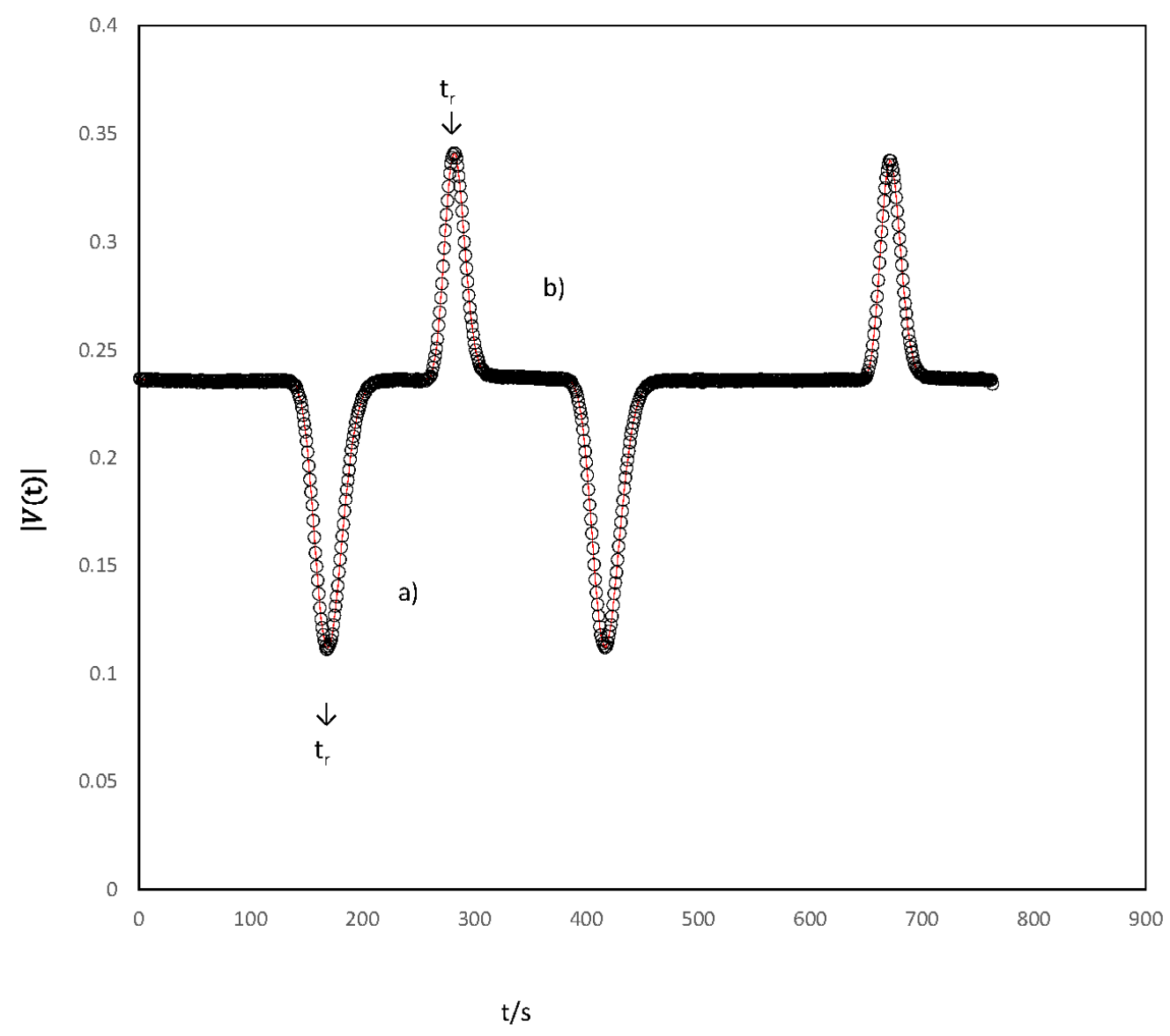

Figure 1. Ternary dispersion profiles relative to \{chloroquine diphosphate (CDP) $\left(C_{1}\right)+\beta$-cyclodextrin $\left(\beta\right.$-CD) $\left.\left(C_{2}\right)\right\}$ solutions generated by injecting: (a) a $0.063 \mathrm{~cm}^{3}$ sample of chloroquine diphosphate $0.005 \mathrm{~mol} \mathrm{dm}^{-3}$ into $0.007 \mathrm{~mol} \mathrm{dm}-3$ $\beta$-cyclodextrin (profile $\Delta C_{1}=0.005 \mathrm{~mol} \mathrm{dm}{ }^{-3}, \Delta C_{2}=0$ ); (b) a $0.063 \mathrm{~cm}^{3}$ sample of 0.002 mol dm $\mathrm{dm}^{-3} \beta$-cyclodextrin into $0.007 \mathrm{~mol} \mathrm{dm}^{-3} \beta$-cyclodextrin (Profile $\Delta C_{1}=0 \mathrm{~mol} \mathrm{dm}{ }^{-3}, \Delta C_{2}=0.002 \mathrm{~mol} \mathrm{dm}^{-3}$ ). Measured (o) and fitted (-, Equation (5)). $t_{\mathrm{R}}$ represents the mean sample retention time.

$D_{1}$ and $D_{2}$ are the eigenvalues of the matrix of $D_{\mathrm{ik}}$ coefficients (Equations (7) and (8)) and $\alpha_{1}$ is the fraction of the initial refractive index difference due to CDP. $R_{1}$ and $R_{2}$ are the detector sensitivities for CDP and $\beta-C D$, respectively: $R_{1}=\partial V / \partial C_{1}$ and $R_{2}=\partial V / \partial C_{2}$.

$$
\begin{aligned}
& D_{1}=\left\{D_{11}+D_{22}+\left(D_{11} D_{22}\right) \sqrt{1+\left[4 D_{12} D_{21} /\left(D_{11} D_{22}\right)^{2}\right]}\right\} / 2 \\
& D_{2}=\left\{D_{11}+D_{22}\left(D_{11} D_{22}\right) \sqrt{1+\left[4 D_{12} D_{21} /\left(D_{11} D_{22}\right)^{2}\right]}\right\} / 2
\end{aligned}
$$

Equation (5) was fitted to pairs of ternary profiles measured for $\alpha_{1} \approx 0$ (initial CDP concentration difference) and $\alpha_{1} \approx 1$ (initial $\beta$-CD concentration difference). $D_{\mathrm{ik}}$ were determined from the relative detector sensitivity $R_{2} / R_{1}$ and the $D_{1}, D_{2}, a, b$ fitting parameters, using

$$
\begin{gathered}
D_{11}=D_{1}+\frac{a(1-a-b)}{b}\left(D_{1}-D_{2}\right) \\
D_{12}=\frac{R_{2}}{R_{1}} \frac{a(1-a)}{b}\left(D_{1}-D_{2}\right) \\
D_{21}=\frac{R_{1}}{R_{2}} \frac{(a+b)(1-a-b)}{b}\left(D_{2}-D_{1}\right)
\end{gathered}
$$




$$
D_{22}=D_{2}+\frac{a(1-a-b)}{b}\left(D_{2}-D_{1}\right)
$$

The parameters $a$ and $b$, in these Equations (9)-(12) are defined by

$$
\begin{gathered}
a=\frac{D_{11} D_{1}\left(R_{1} / R_{2}\right) D_{12}}{D_{2} D_{1}} \\
b=\frac{D_{22} D_{11}+\left(R_{1} / R_{2}\right) D_{12}\left(R_{2} / R_{1}\right) D_{21}}{D_{2} D_{1}}
\end{gathered}
$$

\section{Results}

\subsection{Viscosity Measurements}

Viscosity values for CDP solutions both in pure water and in the mixture fwater + $\beta$-CD $\left.0.0070 \mathrm{~mol} \mathrm{dm}^{-3}\right\}$ are reported in Table 2 .

Table 2. Viscosity values of aqueous solutions of chloroquine diphosphate (CDP) in pure water $\left(\eta_{\mathrm{w}}\right)$, and in a $\left\{\right.$ water $+\beta$-CD $\left.0.0070 \mathrm{~mol} \mathrm{dm}^{-3}\right\}$ mixture $\left(\eta_{(w+\beta-\mathrm{CD})}\right)$ as solvent, at $P=101.3 \mathrm{~Pa}$ and at $T=298.15 \mathrm{~K}$.

\begin{tabular}{ccc}
$C$ & $\begin{array}{c}\eta_{\mathbf{w}}{ }^{\mathbf{a}} \\
/(\mathbf{m P a ~ s})\end{array}$ & $\begin{array}{c}\eta_{w+\beta-\mathbf{C D})} \mathbf{b} \\
/(\mathbf{m P a ~ s})\end{array}$ \\
\hline 0.0010 & 0.949 & 0.969 \\
0.0020 & 0.948 & 0.970 \\
0.0050 & 0.952 & 0.972 \\
0.0070 & 0.950 & 0.978 \\
0.0100 & 0.953 & 0.983 \\
\hline
\end{tabular}

a viscosity values of chloroquine diphosphate (CDP) aqueous solutions; ${ }^{b}$ viscosity values of chloroquine diphosphate $(\mathrm{CDP})$ in $\left\{\right.$ water $\left.+\beta-\mathrm{CD} 0.0070 \mathrm{~mol} \mathrm{dm}{ }^{-3}\right\}$ mixed solvent; standard uncertainties are: $u(C)=5 \times 10^{-6}\left(\mathrm{~mol} \mathrm{dm}^{-3}\right)$; $u(\eta) \cong 0,04(\mathrm{mP} . \mathrm{s}) ; u(T)=0.01 \mathrm{~K} ; u(P)=2.03 \mathrm{kPa}$.

\subsection{Diffusion Measurements}

Tables 3 and 4 show the mean values of the diffusion coefficients for binary systems $\left(\mathrm{CDP} / \mathrm{H}_{2} \mathrm{O}\right.$ and $\left.\beta-\mathrm{CD} / \mathrm{H}_{2} \mathrm{O}\right)$ and for the aqueous ternary system: $\mathrm{CDP}(1) / \beta-\mathrm{CD}(2)$, at $298.15 \mathrm{~K}$.

Table 3. Binary diffusion coefficients $(D)$ measured in the present work of both aqueous solutions of chloroquine diphosphate(1) and of $\beta$-cyclodextrin(2), respectively, at $P=101.3 \mathrm{~Pa}$ and at $T=298.15 \mathrm{~K}$.

\begin{tabular}{ccc}
\hline$C /\left(\mathbf{m o l ~ d m}^{-\mathbf{3}}\right)$ & $\mathbf{D}_{\mathbf{1}} /\left(\mathbf{1 0 ^ { - 9 }} \mathbf{m}^{\mathbf{2}} \mathbf{s}^{-\mathbf{1}}\right)$ & $D_{\mathbf{2}} /\left(\mathbf{1 0 ^ { - 9 }} \mathbf{~ m}^{\mathbf{2}} \mathbf{s}^{-\mathbf{1}}\right)^{\mathbf{a}}$ \\
\hline 0.0000 & $0.710^{\mathrm{b}}$ & \\
0.0020 & 0.690 & \\
0.0040 & 0.684 & \\
0.0050 & 0.678 & $0.322^{\mathrm{c}}$ \\
0.0060 & 0.675 & $0.321^{\mathrm{c}}$ \\
0.0070 & 0.672 & $0.319^{\mathrm{c}}$ \\
0.0080 & 0.669 & \\
0.0100 & 0.666 & \\
0.0200 & 0.650 & \\
\hline
\end{tabular}

a [27]. ${ }^{b}$ This value represents the diffusion coefficient at infinitesimal concentration estimated by extrapolation of our experimental $D$ values here presented, by applying the polynomial: $D=0.715-0.5791 C^{1 / 2}+$ $0.8374 C\left(R^{2}=0.993\right)$, using a least squares procedure. ${ }^{c} D$ values for these concentrations were measured in the present work. Standard uncertainties are: $u(C)=5 \times 10^{-6}\left(\mathrm{~mol} \mathrm{dm}^{-3}\right) ; u(D) \cong 0.01 \times 10^{-9}\left(\mathrm{~m}^{2} \mathrm{~s}^{-1}\right) ; u(T)=0.01 \mathrm{~K}$; $u(P)=2.03 \mathrm{kPa}$. 
Table 4. Ternary mutual diffusion coefficients $\left(D_{11}, D_{12}, D_{21}, D_{22}\right)$ of aqueous \{chloroquine diphosphate $(\mathrm{CDP})\left(C_{1}\right)+$ $\beta$-cyclodextrin $\left(\beta\right.$-CD) $\left.\left(C_{2}\right)\right\}$ solutions at $P=101.3 \mathrm{~Pa}$ and at $T=298.15 \mathrm{~K}$.

\begin{tabular}{ccccccc}
\hline $\boldsymbol{C}_{\mathbf{1}}{ }^{\mathbf{a}}$ & $\boldsymbol{C}_{\mathbf{2}}{ }^{\mathbf{a}}$ & $\boldsymbol{X}_{\mathbf{1}}$ & $\boldsymbol{D}_{\mathbf{1 1}} \pm \boldsymbol{S}_{\mathbf{D}} \mathbf{b}^{\mathbf{b}}$ & $\boldsymbol{D}_{\mathbf{1 2}} \pm \boldsymbol{S}_{\mathbf{D}} \mathbf{b}^{\mathbf{b}}$ & $\boldsymbol{D}_{\mathbf{2 1}} \pm \boldsymbol{S}_{\mathbf{D}}^{\mathbf{b}}$ & $\boldsymbol{D}_{\mathbf{2 2}} \pm \boldsymbol{S}_{\mathbf{D}} \mathbf{b}^{\mathbf{b}}$ \\
\hline 0.0000 & 0.0070 & 0.000 & $0.689 \pm 0.017$ & $0.020 \pm 0.020$ & $-0.031 \pm 0.015$ & $0.383 \pm 0.010$ \\
0.0010 & 0.0070 & 0.014 & $0.686 \pm 0.012$ & $0.004 \pm 0.010$ & $-0.010 \pm 0.010$ & $0.350 \pm 0.020$ \\
0.0020 & 0.0050 & 0.250 & $0.602 \pm 0.012$ & $-0.030 \pm 0.010$ & $0.021 \pm 0.020$ & $0.330 \pm 0.020$ \\
0.0035 & 0.0035 & 0.500 & $0.567 \pm 0.010$ & $-0.028 \pm 0.011$ & $0.020 \pm 0.010$ & $0.349 \pm 0.015$ \\
0.0050 & 0.0020 & 0.750 & $0.594 \pm 0.015$ & $0.129 \pm 0.012$ & $0.018 \pm 0.015$ & $0.342 \pm 0.010$ \\
0.0070 & 0.0000 & 1.000 & $0.670 \pm 0.012$ & $0.180 \pm 0.012$ & $0.010 \pm 0.005$ & $0.390 \pm 0.011$ \\
0.0100 & 0.0000 & 1.000 & $0.667 \pm 0.015$ & $0.197 \pm 0.060$ & $-0.001 \pm 0.001$ & $0.395 \pm 0.012$ \\
\hline
\end{tabular}

${ }^{\mathrm{a}} C_{1}$ and $C_{2}$ in units of $\left(\mathrm{mol} \mathrm{dm}{ }^{-3}\right){ }^{\mathrm{b}}\left(D_{\mathrm{ik}} \pm S_{\mathrm{D}}\right)$ in units of $\left(10^{-9} \mathrm{~m}^{2} \mathrm{~s}^{-1}\right) \cdot u(C)=5 \times 10^{-6}\left(\mathrm{~mol} \mathrm{dm}^{-3}\right) ; u(T)=0.01 \mathrm{~K} ; u(P)=2.03 \mathrm{kPa}$.

Mutual binary diffusion coefficients, $D$, of CDP in aqueous solutions, in Table 3, denote the average ones from, at least, four independent experiments. Good reproducibility (within $\pm 1 \%$ ) was obtained.

Table 4 show the average $\left(D_{11}, D_{12}, D_{21}, D_{22}\right)$ values of aqueous \{chloroquine diphosphate $(\mathrm{CDP})\left(C_{1}\right)+\beta$-cyclodextrin $\left(\beta\right.$-CD) $\left.\left(C_{2}\right)\right\}$ solutions determined for each carrier solution composition by fitting Equation (5) to five replicate pairs of dispersion profiles. Main diffusion coefficients $D_{11}$ and $D_{22}$ were generally reproducible within $\pm 0.015 \times 10^{-9} \mathrm{~m}^{2} \mathrm{~s}^{-1}$. Crossdiffusion coefficients $D_{12}$ and $D_{21}$, describing the coupled diffusion of CDP and $\beta$-CD; they were reproducible within $\pm 0.050 \times 10^{-9} \mathrm{~m}^{2} \mathrm{~s}^{-1}$.

The main diffusion coefficients $D_{11}$ and $D_{22}$, which give the molar fluxes of the CDP (1) and $\beta$-CD (2) components, respectively, driven by their own concentration gradients, are compared with those obtained for the binary systems (CDP/water and $\beta$-CD/water [27] - Table 3).

It should be noted that $D_{11}$ values are higher than the $D_{22}$ ones, and, in general, lower than the binary $D$ of CDP in pure water (deviations between 0.1 and $17 \%$; Table 3 ). However, the values found for $D_{22}$ are similar to those of the binary diffusion coefficients reported for $\beta$-CD in aqueous solution [27]. These results indicate that while the addition of CDP produces relatively small changes in the diffusion coefficient of $\beta-C D\left(D_{22}\right)$, the addition of $\beta$-CD leads to important changes in that of $\operatorname{CDP}\left(D_{11}\right)$ (up to $13 \%$ ). This effect of decrease in the diffusion of CDP, due to the presence of $\beta-C D$, is also highlighted by the positive values of the $D_{12}$ cross-diffusion coefficients, from which it can be concluded that in solutions containing CDP at concentrations $0.0050,0.0070$ and $0.0100 \mathrm{~mol} \mathrm{dm}^{-3}$, for which $D_{12}>0$ (Table 4 ), the gradient in the concentration of $\beta$-CD produces co-current coupled flows of CDP. Nevertheless, because the $D_{21}$ values are almost zero, the CDP concentration gradient leads to weak countercurrent coupled flows of $\beta$-CD.

Considering that the $D_{12} / D_{22}$ ratio gives the number of moles of CDP transported per mole of $\beta$-CD, we may state that one mole of diffusing $\beta$-CD co-transports as a maximum 0.5 moles of CDP. Through the $D_{21} / D_{11}$ values, at the same concentrations, we can expect that one mole of diffusing CDP counter transports at most 0.04 moles of $\beta$-CD.

This behavior can be justified assuming the occurrence of CDP aggregates, with lower mobility and, consequently, being responsible for $D_{11}$ decreasing. This effect is less relevant when we consider the effect of CDP on transport of $\beta-C D$, probably due to the resemblance of the mobilities of $\beta$-CD-free species and eventual aggregates of CDP and $\beta$-CD.

\section{Discussion}

The analysis of the dependence of the viscosity on the concentration was assessed by fitting the values of relative viscosity, $\eta_{r}$, to the Jones-Dole equation (Equation (15)) $[28,29]$

$$
\eta_{r}=\frac{\eta}{\eta_{0}}=1+A C^{1 / 2}+B C
$$

where $A$ and $B$ are empirical terms and $C$ as the same meaning as before.

Being $A$ and $\mathrm{B}$ coefficients related with the long-distance solute-solute interactions and to the solute-solvent interactions, respectively, through their values, it is possible 
to analyze the structure-making or structure-breaking character of the electrolyte in the solution. That is, when coefficient $B$ is positive, we can say that the solute has an organizing capacity of the solvent structure (structure-making character). Contrariwise, a negative value of the $B$ coefficient is related to a solute with the ability to break the structure of water (structure-breaking character) [30].

From the fitting of the viscosity values of the CDP aqueous solutions (Table 2) to the JonesDole equation [28,29], we have obtained $A=1.75 \mathrm{dm}^{3 / 2} \mathrm{~mol}^{-1 / 2}$ and $B=-10.6 \mathrm{dm}^{3} \mathrm{~mol}^{-1}$. The small positive $A$ value and the negative $B$ value suggest that weak interactions between CDP-CDP entities are present, and CDP is a structure-breaking solute (chaotropic solute) [31].

With the purpose of evaluating the changes occurring in the structure and behavior of this solute when $\beta-C D$ is present in the aqueous medium, viscosity measurements in a $\left\{\right.$ water $\left.+\beta-C D 0.007 \mathrm{~mol} \mathrm{dm}^{-3}\right\}$ mixture were carried out and the results also evaluated with the Jones-Dole equation. From this, slightly higher values for $A$ and $B$ parameters (that is, $A=2.39 \mathrm{dm}^{3 / 2} \mathrm{~mol}^{-1 / 2}$ and $B=-14.2 \mathrm{dm}^{3} \mathrm{~mol}^{-1}$ ) were obtained, indicating that the situation is similar.

The interpretation of these data can be also achieved, by a more detailed treatment of the diffusion with supramolecular complexes, using some assumptions. That theory has been developed and well described in the literature [32-35]; In addition, the computation of ternary diffusion coefficients is also described in detail in the Supplementary Material; consequently, only some points are shown in this section.

Another approach to these data can be performed by assuming the occurrence of a 1:1 supramolecular complex between chloroquine diphosphate (CDP) and $\beta$-cyclodextrin ( $\beta$-CD), (Equation (16))

$$
\mathrm{CDP}+\beta-\mathrm{CD} \leftrightarrows \mathrm{CDP}-\beta-\mathrm{CD}
$$

where the association constant, $K$, that describes the stability of these complexes, is given by Equation (17).

$$
K=\frac{C_{\mathrm{CDP}-\beta-\mathrm{CD}}}{C_{\mathrm{CDP}} C_{\beta-\mathrm{CD}}}
$$

$C_{\mathrm{CDP}}, C_{\beta}{ }^{-} \mathrm{CD}$ and $C_{\mathrm{CDP}-\beta-\mathrm{CD}}$ represent the concentrations of free $\mathrm{CDP}$ and $\beta-\mathrm{CD}$, and the concentration of the $\mathrm{CDP}-\beta-\mathrm{CD}$ complex, respectively, which are correlated by the following mass balance equations,

$$
\begin{gathered}
C_{1}=C_{\mathrm{CDP}}+C_{\mathrm{CDP}-\beta-\mathrm{CD}} \\
C_{2}=C_{\mathrm{CD}}+C_{\mathrm{CDP}-\beta-\mathrm{CD}}
\end{gathered}
$$

Identifying these solute species as $\mathrm{CDP}=1, \beta-\mathrm{CD}=2$, and $\mathrm{CDP}-\beta-\mathrm{CD}$ complexes $=3$, respectively, which are in equilibrium according to the equation (Equation (16)), the Equations (3) and (4)), should be replaced by

$$
\begin{aligned}
& J_{1}=-D_{11} \nabla C_{1}-D_{12} \nabla C_{2}-D_{13} \nabla C_{3} \\
& J_{2}=-D_{21} \nabla C_{1}-D_{22} \nabla C_{2}-D_{23} \nabla C_{3} \\
& J_{3}=-D_{31} \nabla C_{1}-D_{32} \nabla C_{2}-D_{33} \nabla C_{3}
\end{aligned}
$$

However, assuming that in diluted solutions that all cross-diffusion terms are negligible $\left(D_{12}, D_{13}, D_{21}, D_{23}, D_{31}, D_{32}=0\right.$ ), and by noting that the total CDP flux (as well as $\beta$-CD flux) is the sum of the respective fluxes of free and CDP- $\beta$-CD complexes, by inserting this information in the Equations (3) and (4), after some mathematical rearrangement, it is possible to obtain the Equations (22)-(25). These equations supply the relations between the mutual diffusion coefficients $D_{11}, D_{12}, D_{21}, D_{22}$ for the total CDP(1) $+\beta$ - CD(2) solute components, and the diffusion coefficients $D_{\mathrm{CDP}}, D_{\beta-\mathrm{CD}}, D_{\mathrm{CDP}-\beta \text {-CD }}$ which indicate the 
diffusion coefficients of the free $\mathrm{CDP}$, the free $\beta-\mathrm{CD}$ and the corresponding supramolecular complex, respectively.

$$
\begin{aligned}
& D_{11}=\frac{1}{2}\left\{\left(D_{\mathrm{CDP}}+\left(D_{\mathrm{CDP}-\beta-\mathrm{CD}}\right)\right)+\left(D_{\mathrm{CDP}}-\left(D_{\mathrm{CDP}-\beta-\mathrm{CD}}\right)\right)\left[1-K\left(c_{2}-c_{1}\right)\right] R\right\} \\
& D_{12}=\frac{1}{2}\left\{\left(\left(D_{\mathrm{CDP}-\beta-\mathrm{CD}}\right)-D_{\mathrm{CDP}}\right)+\left(D_{\mathrm{CDP}}-\left(D_{\mathrm{CDP}-\beta-\mathrm{CD}}\right)\right)\left[1-K\left(c_{2}-c_{1}\right)\right] R\right\} \\
& D_{21}=\frac{1}{2}\left\{\left(\left(D_{\mathrm{CDP}-\beta-\mathrm{CD}}\right)-D_{-\mathrm{CD}}\right)+\left(D_{-\mathrm{CD}}-\left(D_{\mathrm{CDP}-\beta-\mathrm{CD}}\right)\right)\left[1-K\left(c_{2}-c_{1}\right)\right] R\right\} \\
& D_{22}=\frac{1}{2}\left\{\left(D_{-\mathrm{CD}}+\left(D_{\mathrm{CDP}-\beta-\mathrm{CD}}\right)\right)+\left(D_{-\mathrm{CD}}-\left(D_{\mathrm{CDP}-\beta-\mathrm{CD}}\right)\right)\left[1-K\left(c_{2}-c_{1}\right)\right] R\right\}
\end{aligned}
$$

where

$$
R=\left\{\left[1+K\left(c_{2}-c_{1}\right)\right]^{2}+4 K c_{1}\right\}^{-1 / 2}
$$

The computed values for the limiting diffusion coefficients, $D_{\mathrm{s}}$, of species CDP, $\beta$-CD and $C D P-\beta-C D$ are reported in Table 5.

Table 5. Diffusion coefficients, $D_{\mathrm{s}}$, of species at infinitesimal concentration and $T=298.15 \mathrm{~K}$ and $P=101.3 \mathrm{kPa}$.

\begin{tabular}{cc}
\hline Species & $\boldsymbol{D}_{\mathbf{s}} /\left(\mathbf{1 0}^{-\mathbf{9}} \mathbf{~ m}^{\mathbf{2}} \mathbf{s}^{-\mathbf{1}}\right)$ \\
\hline Chloroquine diphosphate (CDP) & 0.670 \\
$\beta$-cyclodextrin $(\beta-C D)$ & 0.380 \\
CDP- $\beta$-CD & 0.360 \\
\hline
\end{tabular}

Standard uncertainties are: $u(T)=0.01 \mathrm{~K} ; u(P)=2.03 \mathrm{kPa}$.

From $D_{11}$ at $X_{1}=1$ and from $D_{22}$ at $X_{1}=0$, the diffusion coefficients of free CDP $\left(D_{\mathrm{CDP}}=0.670 \times 10^{-9} \mathrm{~m}^{2} \mathrm{~s}^{-1}\right)$ and free $\beta$-cyclodextrin $\left(D_{\beta-\mathrm{CD}}=0.380 \times 10^{-9} \mathrm{~m}^{2} \mathrm{~s}^{-1}\right)$ are obtained, respectively.

By using the equation of Stokes-Einstein (Equations (26) and (27)):

$$
\begin{gathered}
D=\frac{k_{B} T}{6 \pi \eta r_{h}} \\
D_{\mathrm{CDP}-\beta-\mathrm{CD}}=\left(D_{\mathrm{CDP}}^{3}+D_{\beta-\mathrm{CD}}^{3}\right)^{1 / 3}
\end{gathered}
$$

where $k_{\mathrm{B}}$ is the Boltzmann constant, $T$ is the absolute temperature and $\eta$ is the viscosity of the solvent, the diffusion coefficient of the CDP- $\beta-\mathrm{CD}$ complex can be estimated as equal to $D_{\mathrm{CDP}-\beta-\mathrm{CD}}=0.360 \times 10^{-9} \mathrm{~m}^{2} \mathrm{~s}^{-1}$.

$K$, was chosen in order to obtain the best agreement between these theoretical values (Equations (22)-25)) and the experimental Dij data. In the present case, for CDP molar factions $X_{1} \leq 0.5$, a complexation constant $K$ equal to $30.0( \pm 0.8) \mathrm{mol}^{-1} \mathrm{dm}^{3}$ was found.

This value demonstrates that the interaction between $\beta$-CD and CDP is weak, which can easily be justified by the high solubility of CDP in water, suggesting that the H-bonding plays an important role in the interactions between CDP and water and, probably, $\mathrm{CDP}$ and $\beta$-CD $[9,36]$. This is in line with similar systems involving other drugs such as, for example, L-dopa and paracetamol $[37,38]$. However, for $X_{1}>0.5$, the model is not applicable. In fact, for these concentrations, the gradient in the concentration of $\beta$-CD produces significant co-current coupled flows of CDP and, therefore, leads to disadvantageous conditions for the formation of supramolecular complexes with this sterically hindered cyclodextrin in solution. This fact is in complete agreement with the viscosity results. That is, CDP is a structure-breaking solute, suggesting that, indeed, there is no complexation between $\beta$-CD and CDP. 


\section{Conclusions}

We can conclude that the diffusion of the CDP is influenced by the presence of this macromolecular cyclodextrin $(\beta-C D)$, suggesting that at low concentrations of this drug there is a very weak interaction between these solutes (which is supported by the small value that can be estimated for the equilibrium constant of the complexation between both solutes, CDP and $\left.\beta-\mathrm{CD}, \mathrm{K}=(30 \pm 0.8) \mathrm{mol}^{-1} \mathrm{dm}^{3}\right)$. This result is consistent with weak chloroquine binding to cyclodextrin, in contrast to a recent report of anomalously large-chloroquine binding constants. For more concentrated solutions, for which it is obtained that $D_{12}>0$, a coflow of CDP is observed, showing thus, there is no predisposition of inclusion of CDP in the cavity of the sterically hindered $\beta$-CD. Support for this evidence is given by the viscosity data measured.

Supplementary Materials: The following are available online at https:/ /www.mdpi.com/article/10 $.3390 / \mathrm{pr} 9081433 / \mathrm{s} 1$, The theoretical computation of the ternary diffusion coefficients, contemplating the for-mation of supramolecular complexes, is described in detail in the Supplementary Material.

Author Contributions: Conceptualization, A.C.F.R. and A.M.; methodology, A.C.F.R. and A.M.; software, A.C.F.R., L.M., A.M., E.F.G.A.; M.M.R., M.A.E. and A.J.M.V.; validation, A.C.F.R., L.M., A.M., A.J.M.V. and M.A.E.; formal analysis, A.C.F.R., A.M., M.A.E. and A.J.M.V.; investigation, A.C.F.R., L.M., A.M., E.F.G.A.; M.M.R.; A.J.M.V. and M.A.E.; resources, A.C.F.R. and A.M.; data curation, L.M.; A.C.F.R. and A.M.; writing-original draft preparation, A.C.F.R. and A.M.; writing-review and editing, A.C.F.R., A.M.; M.A.E. and A.J.M.V.; visualization, A.C.F.R., A.M., M.A.E. and A.J.M.V.; supervision, A.C.F.R. and A.M.; project administration, A.C.F.R. and A.M.; funding acquisition, A.C.F.R. and A.M. All authors have read and agreed to the published version of the manuscript.

Funding: The authors in Coimbra are grateful for funding from "The Coimbra Chemistry Centre" which is supported by the Fundação para a Ciência e a Tecnologia (FCT), Portuguese Agency for Scientific Research, through the programs UID/QUI/UI0313/2019 and COMPETE. The authors in Zlín are grateful for research funding by the Ministry of Education, Youth and Sports of the Czech Republic DKRVO (RP/CPS/2020/003). MMR is thankful to the University of Alcalá (Spain) for the financial assistance (Mobility Grants for Researchers-2021).

Institutional Review Board Statement: Not applicable.

Informed Consent Statement: Not applicable.

Data Availability Statement: Not applicable.

Acknowledgments: We are thankful to António M.C. Ferreira for the technical support for diffusion technique maintenance and to Master L.M.P. Verissimo for discussions about the drug.

Conflicts of Interest: The authors declare that they have no known competing financial interests or personal relationships that could have appeared to influence the work reported in this paper. The authors declare no conflict of interest.

\section{References}

1. Daneshfar, A.; Vafafard, S. Solubility of Chloroquine Diphosphate and 4,7-Dichloroquinoline in Water, Ethanol, Tetrahydrofuran, Acetonitrile, and Acetone from (298.2 to 333.2) K. J. Chem. Eng. Data 2009, 54, 2170-2173. [CrossRef]

2. Roy, A.; Saha, S.; Roy, D.; Bhattacharyya, S.; Roy, M.N. Formation \& specification of host-guest inclusion complexes of an anti-malarial drug inside into cyclic oligosaccharides for enhancing bioavailability. J. Incl. Phenom. Macrocycl. Chem. 2020, 97, 65-76. [CrossRef]

3. Kamitsuji, Y.; Kuroda, J.; Kimura, S.; Toyokuni, S.; Watanabe, K.; Ashihara, E.; Tanaka, H.; Yui, Y.; Watanabe, M.; Matsubara, H.; et al. The Bcr-Abl kinase inhibitor INNO-406 induces autophagy and different modes of cell death execution in Bcr-Abl-positive leukemias. Cell Death Differ. 2008, 15, 1712-1722. [CrossRef]

4. Furst, D.E. Pharmacokinetics of hydroxychloroquine and chloroquine during treatment of rheumatic diseases. Lupus 1996, 5, 11-15. [CrossRef]

5. Verbeeck, R.K.; Junginger, H.E.; Midha, K.K.; Shah, V.P.; Barends, D.M. Biowaiver monographs for immediate release solid oral dosage forms based on biopharmaceutics classification system (BCS) literature data: Chloroquine phosphate, chloroquine sulfate, and chloroquine hydrochloride.This study reflects the scientific opinion. J. Pharm. Sci. 2005, 1389-1395. [CrossRef] 
6. Yao, X.; Ye, F.; Zhang, M.; Cui, C.; Huang, B.; Niu, P.; Liu, X.; Zhao, L.; Dong, E.; Song, C.; et al. In Vitro Antiviral Activity and Projection of Optimized Dosing Design of Hydroxychloroquine for the Treatment of Severe Acute Respiratory Syndrome Coronavirus 2 (SARS-CoV-2). Clin. Infect. Dis. 2020, 71, 732-739. [CrossRef]

7. Braga, C.B.; Martins, A.C.; Cayotopa, A.D.E.; Klein, W.W.; Schlosser, A.R.; Silva, A.F.; Sousa, M.N.; Andrade, B.W.B.; Junior, J.A.F.; Pinto, W.J.; et al. Side Effects of Chloroquine and Primaquine and Symptom Reduction in Malaria Endemic Area (Mâncio Lima, Acre, Brazil). Interdiscip. Perspect. Infect. Dis. 2015, 2015, 346853. [CrossRef]

8. Carneiro, S.B.; Duarte, F.I.C.; Heimfarth, L.; Quintans, J.S.S.; Quintans-Junior, L.J.; Junior, V.F.V.; Lima, A.A.N. Cyclodextrin-Drug Inclusion Complexes: In Vivo and In Vitro Approaches. Int. J. Mol. Sci. 2019, 20, 642. [CrossRef]

9. Valente, A.J.; Soderman, O. The formation of host-guest complexes between surfactants and cyclodextrins. Adv. Colloid Interface Sci. 2014, 205, 156. [CrossRef] [PubMed]

10. Niether, D.; Kawaguchi, T.; Hovancova, J.; Eguchi, K.; Dhont, J.K.G.; Kita, R.; Wiegand, S. Role of Hydrogen Bonding of Cyclodextrin-Drug Complexes Probed by Thermodiffusion. Langmuir 2017, 33, 8483. [CrossRef] [PubMed]

11. Ryzhakov, A.; Thi, T.D.; Stappaerts, J.; Bertoletti, L.; Kimpe, K.; Couto, A.R.S.; Saokham, P.; Mooter, G.V.; Augustijns, P.; Somsen, G.W.; et al. Self-Assembly of Cyclodextrins and Their Complexes in Aqueous Solutions. J. Pharm. Sci. 2016, 105, 2556. [CrossRef]

12. Fan, Z.; Diao, C.-H.; Yu, M.; Jing, Z.-L.; Chen, X.; Deng, Q.-L. An Investigation of the Inclusion Complex of $\beta$-Cyclodextrin with 8-Nitro-Quinoline in the Solid State. Supramol. Chem. 2006, 18, 7-11. [CrossRef]

13. Duan, Z.; Bu, T.; Bian, H.; Zhu, L.; Xiang, Y.; Xia, D. Effective Removal of Phenylamine, Quinoline, and Indole from Light Oil by $\beta$-Cyclodextrin Aqueous Solution through Molecular Inclusion. Energy Fuels 2018, 32, 9280-9288. [CrossRef]

14. Assaba, I.M.; Rahali, S.; Belhocine, Y.; Allal, H. Inclusion complexation of chloroquine with $\alpha$ and $\beta$-cyclodextrin: Theoretical insights from the new B97-3c composite method. J. Mol. Struct. 2021, 1227, 129696. [CrossRef]

15. Guoquan, Z.; Tinggong, W.; Danfeng, S.; Jian, S.; Zehui, Y. The solubility and dissolution thermodynamic properties of chloroquine diphosphate in different organic solvents. J. Chem. Thermodyn. 2021, 156, 106368. [CrossRef]

16. Callendar, R.; Leaist, D.G. Diffusion Coefficients for Binary, Ternary, and Polydisperse Solutions from Peak-Width Analysis of Taylor Dispersion Profiles. J. Solut. Chem. 2006, 35, 353-379. [CrossRef]

17. Barthel, J.; Gores, H.J.; Lohr, C.M.; Seidl, J.J. Taylor dispersion measurements at low electrolyte concentrations. I. Tetraalkylammonium perchlorate aqueous solutions. J. Solut. Chem. 1996, 25, 921-935. [CrossRef]

18. Loh, W. A técnica de dispersão de taylor para estudos de difusão em líquidos e suas aplicações. Quim. Nova 1997, 20, 541-545. [CrossRef]

19. Alizadeh, A.; Nieto de Castro, C.A.; Wakeham, W.A. The theory of the Taylor dispersion technique for liquid diffusivity measurements. Int. J. Thermophys. 1980, 1, 243-284. [CrossRef]

20. Price, W.E. Theory of the taylor dispersion technique for three-component-system diffusion measurements. J. Chem. Soc. Faraday Trans. 1 Phys. Chem. Condens. Phases 1988, 84, 2431-2439. [CrossRef]

21. Deng, Z.; Leaist, D.G. Ternary mutual diffusion coefficients of $\mathrm{MgCl} 2+\mathrm{MgSO} 4+\mathrm{H} 2 \mathrm{O}$ and $\mathrm{Na} 2 \mathrm{SO} 4+\mathrm{MgSO} 4+\mathrm{H} 2 \mathrm{O}$ from Taylor dispersion profiles. Can. J. Chem. 1991, 69, 1548-1553. [CrossRef]

22. Taylor, G. Dispersion of Soluble Matter in Solvent Flowing Slowly through a Tube. Proc. R. Soc. Lond. A 1953, $219,186-203$. [CrossRef]

23. Taylor, G. The dispersion of matter in turbulent flow through a pipe. Proc. R. Soc. Lond. A 1954, 223, 446-468. [CrossRef]

24. Taylor, G. Conditions under which dispersion of a solute in a stream of solvent can be used to measure molecular diffusion. Proc. R. Soc. Lond. A. 1954, 225, 473-477. [CrossRef]

25. Leaist, D.G. Determination of ternary diffusion coefficients by the Taylor dispersion method. J. Phys. Chem. 1990, 94, 5180-5183. [CrossRef]

26. Leaist, D.G. Ternary diffusion coefficients of 18-crown-6 ether-KCl-water by direct least-squares analysis of Taylor dispersion measurements. J. Chem. Soc. Faraday Trans. 1991, 87, 597-601. [CrossRef]

27. Ribeiro, A.C.; Leaist, D.G.; Esteso, M.A.; Lobo, V.M.; Valente, A.J.; Santos, C.I.; Cabral, A.M.; Veiga, F.J. Binary Mutual Diffusion Coefficients of Aqueous Solutions of $\beta$-Cyclodextrin at Temperatures from 298.15 to 312.15 K. J. Chem. Eng. Data 2006, 51, 1368-1371. [CrossRef]

28. Jones, G.; Christian, S.M. The Viscosity of Aqueous Solutions of Electrolytes as a Function of the Concentration. V. Sodium Chloride. J. Am. Chem. Soc. 1937, 59, 484-486. [CrossRef]

29. Jones, G.; Dole, M. The viscosity of aqueous solutions of strong electrolytes with special reference to barium chloride. J. Am. Chem. Soc. 1929, 2950-2964. [CrossRef]

30. Marcus, Y. Effect of Ions on the Structure of Water: Structure Making and Breaking. Chem. Rev. 2009, 109, 1346-1370. [CrossRef]

31. Musilová, L.; Mráček, A.; Kašpárková, V.; Minař́́k, A.; Valente, A.J.; Azevedo, E.F.; Verissimo, L.M.; Rodrigo, M.M.; Esteso, M.A.; Ribeiro, A.C. Effect of Hofmeister Ions on Transport Properties of Aqueous Solutions of Sodium Hyaluronate. Int. J. Mol. Sci. 2021, 22, 1932. [CrossRef]

32. Paduano, L.; Sartorio, R.; Vitagliano, V.; Castronuovo, G. Calorimetric and diffusional behaviour of the system $\alpha$-cyclodextrin-Lphenylalanine in aqueous solution. Thermochim. Acta 1990, 162, 155-161. [CrossRef]

33. Paduano, L.; Sartorio, R.; Vitagliano, V.; Costantino, L. Diffusion coefficients in systems with inclusion compounds. Part 2. $\alpha$-Cyclodextrin-(DL)norleucine-water at $25^{\circ} \mathrm{C}$. Ber. Bunsenges. Phys. Chem. 1990, 94, 741-745. [CrossRef] 
34. Paduano, L.; Vergara, A.; Corradino, M.R.; Vitagliano, V.; Sartorio, R. Equilibrium properties of the system (dibutyl L-tartrate)-( $\alpha$ cyclodextrin)-(water) at $25^{\circ} \mathrm{C}$. A $1 \mathrm{H}$ NMR and UV study. Phys. Chem. Chem. Phys. 1999, 1, 3627-3631. [CrossRef]

35. Paduano, L.; Sartorio, R.; Vitagliano, V. Diffusion coefficients of the ternary system $\alpha$-cyclodextrin-sodium benzenesulfonate-water at $25{ }^{\circ} \mathrm{C}$ : The effect of chemical equilibrium and complex formation on the diffusion coefficients of a ternary system. J. Phys. Chem. B 1998, 102, 5023-5028. [CrossRef]

36. Saenger, W.; Steiner, T. Cyclodextrin Inclusion Complexes: Host-Guest Interactions and Hydrogen-Bonding Networks. Acta Crystallogr. Sect. A Found. Crystallogr. 1998, 54, 798-805. [CrossRef]

37. Barros, M.C.; Ramos, M.L.; Burrows, H.D.; Esteso, M.A.; Leaist, D.G.; Ribeiro, A.C. Ternary mutual diffusion coefficients of aqueous $\{1$-dopa $(1)+\beta-C D(2)\}$ solutions at $T=298.15 \mathrm{~K}$. J. Chem. Thermodyn. 2015, 90, 169-173. [CrossRef]

38. Ribeiro, A.C.; Musilová, L.; Mráček, A.; Cabral, A.M.; Santos, M.A.; Cabral, I.; Esteso, M.A.; Valente, A.J.M.; Leaist, D. Host-guest paracetamol/cyclodextrin complex formation evaluated from coupled diffusion measurements. J. Chem. Thermodyn. 2021, 161, 106551. [CrossRef] 